\title{
Are Oxygen-Conserving Devices Effective for Correcting Exercise Hypoxemia?
}

\author{
Sergi Martí MD, Virginia Pajares MD, Fátima Morante RN, Maria-Antònia Ramón PT, \\ Jordi Lara, Jaume Ferrer MD, and Maria-Rosa Güell MD
}

\begin{abstract}
BACKGROUND: Correction of exercise hypoxemia in advanced lung diseases is crucial and often challenging. However, oxygen-conserving devices have been introduced in the market with limited evidence of effectiveness. In the present study the efficacy of 2 oxygen-conserving devices, a pulse demand oxygen delivery (DOD) system and pendant reservoir cannula (PRC), were evaluated in subjects with COPD and interstitial lung disease (ILD). METHODS: A cross-sectional, crossover study included 28 COPD and 31 ILD subjects with oxygen desaturation on the 6-min walk test (average $\mathrm{S}_{\mathrm{pO}_{2}}<88 \%$ ). Each subject underwent 3 walk tests with DOD, PRC, and continuous oxygen flow by standard nasal cannula (CFNC), in random order, taking average $\mathrm{S}_{\mathrm{pO}_{2}} \geq 90 \%$ as the resaturation criterion. RESULTS: Exercise desaturation was corrected in $79 \%$, $79 \%$, and $86 \%$ of COPD subjects with CFNC, DOD, and PRC, respectively, and in $77 \%, 61 \%$, and $81 \%$ of ILD subjects with CFNC, DOD, and PRC, respectively. When compared to CFNC, the oxygen-conserving devices showed similar efficacy, except a lower performance for the DOD in the ILD subjects $(P=.01)$. CONCLUSIONS: Although these oxygen-conserving devices corrected exercise hypoxemia in most COPD and ILD subjects, correction was not achieved in about $20 \%$ of the severe COPD subjects, regardless of the device, and in nearly $40 \%$ of the ILD subjects with the DOD device. These findings underscore that individualized adjustment of oxygen flow is needed for optimal correction of exercise hypoxemia, especially with a DOD in an ILD patient. (Clinical Trials.gov NCT01086891). Key words: COPD; conservers; exercise test; interstitial lung disease; oxygen inhalation therapy; technology assessment. [Respir Care 2013;58(10):1606-1613. () 2013 Daedalus Enterprises]
\end{abstract}

\section{Introduction}

The use of supplemental oxygen during exercise reduces dyspnea and improves exercise performance in patients with hypoxemia due to $\mathrm{COPD}^{1,2}$ or interstitial lung disease (ILD). ${ }^{3,4}$ Traditional portable systems deliver continuous flow oxygen, most of which does not reach the alveoli. Consequently, a considerable amount of oxygen is

\footnotetext{
Dr Martí, Ms Ramón, and Dr Ferrer are affiliated with the Pulmonology Department, Hospital Universitari Vall d'Hebron, and the Department of Medicine, Universitat Autònoma de Barcelona, Barcelona, Spain, and with the Centro de Investigación Biomédica en Red de Enfermedades Respiratorias, Instituto de Salud Carlos III, Madrid, Spain. Dr Pajares, Ms Morante, and Dr Güell are affiliated with the Pulmonology Department, Hospital Santa Creu i Sant Pau, Barcelona, Spain. Mr Lara is affiliated with the Laboratory of Biostatistics and Epidemiology, Universitat Autònoma de Barcelona, Barcelona, Spain.
}

wasted. Moreover, these systems are bulky, and the duration of oxygen delivery away from the stationary equipment is limited, thus reducing the patient's mobility and independence.

The development of oxygen-conserving devices has led to lighter-weight systems with longer duration of oxy-

\footnotetext{
This research was partly supported by grants FIS PI07/90074 from Instituto de Salud Carlos III, Madrid, Spain, and FUCAP 2008 from Fundació Catalana de Pneumologia, Barcelona, Spain. Carburos Médica and Oxigen Salud provided the disposable oxygen equipment. The authors have disclosed no other conflicts of interest.

Correspondence: Sergi Martí MD, Pulmonology Department, Hospital Universitari Vall d'Hebron. Passeig Vall d'Hebron 119-129, 08035 Barcelona, Spain. E-mail: smarti@vhebron.net.
}

DOI: $10.4187 /$ respcare.02260 
gen delivery for outdoor mobility. ${ }^{5}$ Currently available oxygen-conserving devices include pulse demand oxygen delivery (DOD) devices and reservoir cannulas. The newer DOD devices are integrated in portable liquid oxygen systems and deliver a pre-set bolus of oxygen only during early inspiration, triggered by the patient's inspiratory effort. Reservoir cannulas store oxygen during exhalation, making it available as a bolus at onset of the next inhalation. Despite these technical advantages, however, many oxygen-conserving devices have been placed on the market with limited published evidence regarding their efficacy. ${ }^{6-8}$

\section{See the Related Editorial on Page 1711}

The equivalency of oxygen-conserving devices to continuous flow oxygen for correcting hypoxemia has been evaluated in several studies. When the patient is at rest, the 2 types of systems have proven to be equivalent. ${ }^{9-11}$ However, when oxygen requirements increase, specifically during exercise ${ }^{10-16}$ and in patients with ILD, ${ }^{17}$ oxygenconserving devices do not seem to provide equivalent benefits.

It has been suggested that oxygen supply should be increased in some patients treated with oxygen-conserving devices, to improve hypoxemia, ${ }^{11,13,17}$ but there have been no studies evaluating in what cases adequate correction fails despite the increased supply.

The primary aim of this study was to assess the efficacy of 2 oxygen-conserving systems (a DOD device and pendant reservoir cannula [PRC]) versus continuous flow oxygen through a standard nasal cannula (CFNC) for correcting oxygen desaturation during exercise in patients with COPD or ILD. In contrast to previous studies, the oxygen delivery settings were individually adjusted with each subject, as needed, to correct hypoxemia. The secondary aim was to determine the subjects' preferences for each of the 3 types of devices tested.

\section{Methods}

The study protocol was approved by the institutional review board of each participating center. The aim of the study was explained to each subject, and written informed consent was obtained from all subjects.

\section{Subjects}

The study population included consecutively enrolled patients with a diagnosis of COPD or ILD with exerciserelated oxygen desaturation, seen between April 2008 and January 2010 in the Oxygen Therapy Control Units of 2 teaching hospitals: Hospital de la Santa Creu i Sant Pau,

\section{QUICK LOOK}

\section{Current knowledge}

Supplemental oxygen during exercise reduces dyspnea and improves exercise performance in patients with hypoxemia due to chronic lung disease. Pulse-dose oxygen systems conserve oxygen, but their ability to reverse exercise hypoxemia is suspect.

\section{What this paper contributes to our knowledge}

During the 6-min walk test, $20 \%$ percent of the subjects with severe COPD and oxygen desaturation failed to achieve re-saturation $\left(\mathrm{S}_{\mathrm{pO}_{2}} \geq 90 \%\right)$, even at the maximum flow provided by the pulse-dose system. With the pulse-dose system, failure to correct exercise desaturation occurred in about $40 \%$ of subjects with interstitial lung disease. Oxygen flow titration during exercise should be accomplished on a per patient basis, with the device being considered for use.

and Hospital Universitari Vall d'Hebron, Barcelona, Spain. In this study exercise desaturation was defined as average $\mathrm{S}_{\mathrm{pO}_{2}}<88 \%$ during the 6-min walk test (6MWT), in order to include patients with sustained exercise desaturation. The exclusion criteria were: active smoker, use of ambulatory oxygen therapy before the study, recent exacerbation (within 4 weeks), severe comorbidity, and locomotor abnormality preventing performance of the 6MWT.

\section{Study Design}

This was an open, cross-sectional, crossover study, carried out on 2 consecutive days.

Day 1. Pulmonary function testing was performed on day 1 (MasterLab, Erich Jaeger/CareFusion, San Diego, California). All tests were done according to the European Respiratory Society and American Thoracic Society guidelines. ${ }^{18-20}$ Static lung volumes were measured using the plethysmography method, and diffusion capacity of the lung for carbon monoxide was measured using the single breath-hold method. ${ }^{21}$ Baseline dyspnea was assessed with the modified Medical Research Council dyspnea scale. ${ }^{22}$ At least 2 6MWT were performed: the first on room air, to confirm desaturation. After a 30-min rest, the second test was carried out with the subject on CFNC. The oxygen flow setting was decided by the pneumologist after the baseline (room air) test was evaluated. Resaturation was defined as maintenance of an average $\mathrm{S}_{\mathrm{pO}_{2}} \geq 90 \%$ during the 6MWT. The oxygen setting was increased in a subsequent 6MWT if needed to achieve resaturation. The ap- 


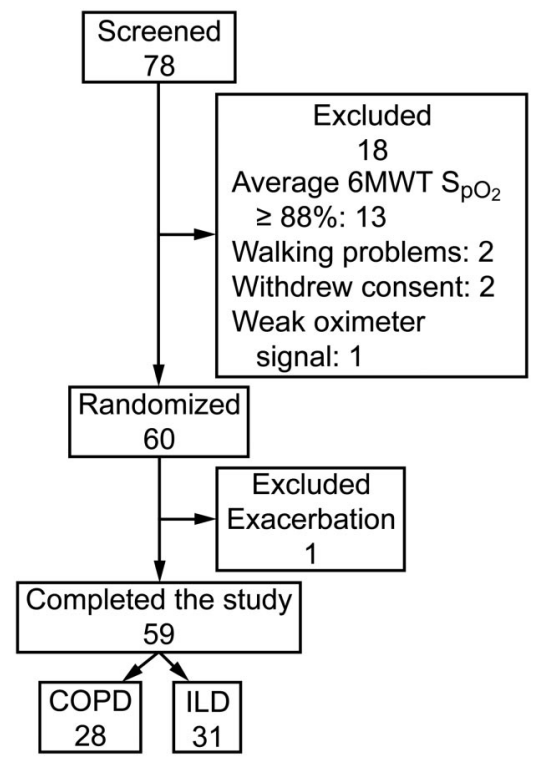

Fig. 1. Flow chart showing subject enrollment. $6 \mathrm{MWT}=6-\mathrm{min}$ walk test. ILD = interstitial lung disease.

propriate oxygen setting to achieve resaturation was established with no more than 3 walk tests. The 6MWT was carried out in a 30-meter-long hall and monitored by a trained nurse, who always used the same expressions of encouragement. ${ }^{23}$ The subjects walked at a rhythm similar to that used in their daily activities, while pulling along an oxygen cylinder in a small, light, wheeled cart, and were instructed to breathe through their nose during the test. We recorded heart rate and $\mathrm{S}_{\mathrm{pO}_{2}}$ (Pulsox 300i, Konica/Minolta, Osaka, Japan).

Day 2. On the second day the subjects performed at least 3 6MWTs, with a 30-min rest between each test, using CFNC, a DOD system (Spirit 300, Caire Medical, Ball Ground, Georgia), and a PRC (Oxymizer Pendant, Chad Therapeutics, Chatsworth, California). The CFNC and PRC were connected to a portable cylinder weighing $3.63 \mathrm{~kg}$ with continuous flow liquid oxygen (Stroller, Caire Medical, Ball Ground, Georgia). The DOD system was integrated with a lighter cylinder $(1.95 \mathrm{~kg})$ with pulse delivery of $15 \mathrm{~mL}$ per setting (that is, setting $1=15 \mathrm{~mL}$, setting $2=30 \mathrm{~mL}$, et cetera). With each subject the 3 devices were tested in random order, assigned using a computergenerated sequence. Oxygen delivery was established as follows. With CFNC the oxygen flow was set according to the adjustment performed on day 1 . With the DOD the setting was the manufacturer's equivalent to the required CFNC flow. With the PRC the initial flow was $1 \mathrm{~L} / \mathrm{min}$ less than the required CFNC flow. With any of the devices, if an average $\mathrm{S}_{\mathrm{pO}_{2}} \geq 90 \%$ was not maintained, the 6MWT was repeated with a higher oxygen setting, up to the maximum possible with the system $(6 \mathrm{~L} / \mathrm{min}$ with con-
Table 1. Subject Characteristics

\begin{tabular}{|c|c|c|}
\hline & $\begin{array}{c}\text { COPD } \\
(n=28)\end{array}$ & $\begin{array}{c}\text { ILD } \\
(n=31)\end{array}$ \\
\hline Age, y & $66.3 \pm 8.6$ & $68.7 \pm 9.9$ \\
\hline Male/female, no. & $23 / 5$ & $19 / 12$ \\
\hline BMI, $\mathrm{kg} / \mathrm{m}^{2}$ & $26.4 \pm 2.8$ & $27.2 \pm 4.9$ \\
\hline $\mathrm{FEV}_{1}, \mathrm{~L}$ & $0.93 \pm 0.36$ & $1.62 \pm 0.45$ \\
\hline $\mathrm{FEV}_{1}, \%$ predicted & $31.0 \pm 10.5$ & $65.5 \pm 15.8$ \\
\hline FVC, L & $2.52 \pm 0.95$ & $1.89 \pm 0.56$ \\
\hline FVC, $\%$ predicted & $59.4 \pm 17.2$ & $56.6 \pm 14.8$ \\
\hline $\mathrm{FEV}_{1} / \mathrm{FVC}$ & $0.39 \pm 0.12$ & $0.86 \pm 0.10$ \\
\hline TLC, $\%$ predicted & $126.0 \pm 24.8$ & $60.1 \pm 14.6$ \\
\hline $\mathrm{RV}, \%$ predicted & $219.0 \pm 71.5$ & $59.2 \pm 23.1$ \\
\hline $\mathrm{D}_{\mathrm{LCO}}, \%$ predicted & $29.6 \pm 10.1$ & $32.3 \pm 11.4$ \\
\hline $\mathrm{P}_{\mathrm{aO}_{2}}, \mathrm{~mm} \mathrm{Hg}$ & $60.2 \pm 6.6$ & $65.3 \pm 10.0$ \\
\hline $\mathrm{P}_{\mathrm{aCO}_{2}}, \mathrm{~mm} \mathrm{Hg}$ & $42.7 \pm 6.1$ & $39.9 \pm 4.7$ \\
\hline $\mathrm{P}_{(\mathrm{A}-\mathrm{a}) \mathrm{O}_{2}}, \mathrm{~mm} \mathrm{Hg}$ & $37.6 \pm 8.3$ & $35.8 \pm 9.7$ \\
\hline MRC dyspnea score $\geq 2$, no. $(\%)$ & $24(85.7)$ & $28(90.3)$ \\
\hline Previous LTOT (not portable), no. (\%) & $14(50.0)$ & $9(29.0)$ \\
\hline $\begin{array}{l}\text { The values are mean } \pm \text { SD unless otherwise indicate } \\
\text { ILD = interstitial lung disease } \\
\text { BMI = body mass index } \\
\text { TLC = total lung capacity } \\
\text { RV = residual volume } \\
\mathrm{D}_{\mathrm{LCO}}=\text { diffusion capacity of the lung for carbon } \mathrm{mc} \\
\mathrm{P}_{(\mathrm{A}-\mathrm{a}) \mathrm{O}_{2}}=\text { alveolar-arterial oxygen difference } \\
\mathrm{MRC}=\text { Medical Research Council } \\
\text { LTOT = long-term oxygen therapy }\end{array}$ & xide & \\
\hline
\end{tabular}

tinuous flow, and setting 5 with the DOD), attempting to correct desaturation. The appropriate oxygen setting to achieve the resaturation criterion was established with no more than 3 walk tests for each device.

\section{Measurements}

The main outcome variable was the percentage of subjects in whom desaturation on exercise was ultimately corrected (average $\mathrm{S}_{\mathrm{pO}_{2}} \geq 90 \%$ ) in the 6MWT with each device. Heart rate, breathing frequency, and dyspnea score (measured with a modified Borg visual analog scale ranging from 0 to $10^{24}$ ) were recorded before and after each 6MWT. If more than one 6MWT was needed with any device, the last measurements were recorded. After the 6MWTs we asked the subjects if they had a preference for any of the 3 devices.

\section{Statistical Analysis}

Sample size was calculated with a chi-square test to compare 2 expected proportions for independent data. The expected proportions of successful response (average $\mathrm{S}_{\mathrm{pO}_{2}} \geq 90 \%$ during the 6MWT) were $60 \%$ and $50 \%$ for DOD in COPD and ILD, respectively, and $90 \%$ and $85 \%$ for PRC. Thus, 30 subjects in each pulmonary disease 
Table 2. Cardiopulmonary Measurements at Rest Before, During, amd After the Baseline Room Air 6-Min Walk Test

\begin{tabular}{lcc}
\hline \hline & $\begin{array}{c}\mathrm{COPD} \\
(n=28)\end{array}$ & $\begin{array}{c}\text { ILD } \\
(n=31)\end{array}$ \\
\hline At rest before 6MWT & & \\
$\mathrm{S}_{\mathrm{pO}_{2}}, \%$ & $91.0 \pm 2.8$ & $92.1 \pm 2.9$ \\
Breathing frequency, breaths/min & $20.7 \pm 4.0$ & $28.3 \pm 6.0$ \\
Heart rate, beats/min & $86.4 \pm 10.4$ & $85.3 \pm 11.6$ \\
Borg dyspnea score & $1.1 \pm 1.3$ & $1.3 \pm 1.5$ \\
During 6MWT & & \\
Average $\mathrm{S}_{\mathrm{pO}_{2}}, \%$ & $81.5 \pm 6$ & $80.4 \pm 6.7$ \\
$\quad$ Time with $\mathrm{S}_{\mathrm{pO}_{2}}<90 \%, \%$ & $92.3 \pm 7.7$ & $80.4 \pm 6.7$ \\
Immediately after 6MWT & & \\
$\quad \mathrm{S}_{\mathrm{pO}_{2}}, \%$ & $78.1 \pm 8.6$ & $76.2 \pm 7.3$ \\
$\quad$ Breathing frequency, breaths/min & $24.8 \pm 4.8$ & $36.5 \pm 7.1$ \\
$\quad$ Heart rate, beats/min & $103.2 \pm 15.5$ & $105.1 \pm 20.0$ \\
$\quad$ Borg dyspnea score & $4.7 \pm 2.2$ & $5.4 \pm 3.0$ \\
6-min walk distance, $\mathrm{m}$ & $325.3 \pm 79.1$ & $344.6 \pm 76.3$ \\
& & \\
\hline The values are mean \pm SD unless otherwise indicated. & & \\
ILD = interstitial lung disease & & \\
6MWT $=$ 6-min walk test & & \\
\hline
\end{tabular}

group would suffice to observe significant differences between the devices, assuming a 2-sided type 1 error of $5 \%$ and a statistical power of $80 \%$.

Baseline data are described as absolute frequency and percentage for qualitative variables, and mean and stan- dard deviation for quantitative variables. Inferential analyses were performed with a general linear model for quantitative variables or a generalized estimated equation for qualitative variables, to assess intra-subject variability, including device, sequence of use, and period as fixed factors, and subject effect nested in sequence as random effect.

Device preference was analyzed using the Prescott test, ${ }^{25}$ which includes the non-preferences, bearing in mind the order in which the devices were tested by the subject. Two-sided significance tests were used throughout, and a $P$ value $<.05$ was considered significant. Statistical analyses were performed with statistics software (SAS 9.1.3, SAS Institute, Cary, North Carolina).

\section{Results}

Subject enrollment is shown in Figure 1. Of the 60 subjects randomized, 59 completed the study: 28 with COPD and 31 with ILD. The ILD diagnoses were: 14 idiopathic pulmonary fibrosis, 7 nonspecific interstitial pneumonia, 7 hypersensitivity pneumonitis, 1 cryptogenic organizing pneumonia, 2 unclassifiable interstitial pneumonia. Carbon monoxide diffusion in both groups was around $30 \%$ of predicted (Table 1), indicating severely impaired respiratory function. The baseline (without oxygen) 6MWT results showed marked desaturation on exer-

Table 3. Cardiopulmonary Measurements in the COPD Subjects at Rest Before, During, and After the 6-Min Walk Test With 3 Oxygen Delivery Systems $(n=28)$

\begin{tabular}{|c|c|c|c|c|c|}
\hline & CFNC & DOD & $\begin{array}{c}P \\
\text { DOD vs CFNC }\end{array}$ & PRC & $\begin{array}{c}P \\
\text { PRC vs CFNC }\end{array}$ \\
\hline \multicolumn{6}{|l|}{ At rest before $6 \mathrm{MWT}$} \\
\hline $\mathrm{S}_{\mathrm{pO}_{2}}, \%$ & $95.9 \pm 0.2$ & $95.6 \pm 0.2$ & .12 & $96.1 \pm 0.2$ & .60 \\
\hline Breathing frequency, breaths/min & $19.3 \pm 0.5$ & $19.0 \pm 0.5$ & .67 & $19.3 \pm 0.5$ & .95 \\
\hline Heart rate, beats/min & $82.0 \pm 1.1$ & $80.5 \pm 1.1$ & .33 & $80.0 \pm 1.1$ & .18 \\
\hline Borg dyspnea score & $0.6 \pm 0.1$ & $0.6 \pm 0.1$ & .56 & $0.5 \pm 0.1$ & .61 \\
\hline \multicolumn{6}{|l|}{ During 6MWT } \\
\hline Average $\mathrm{S}_{\mathrm{pO}_{2}}, \%$ & $90.4 \pm 0.3$ & $91.1 \pm 0.3$ & .07 & $91.6 \pm 0.3$ & .004 \\
\hline Average $\mathrm{S}_{\mathrm{pO}_{2}} \geq 90 \%$, no. $(\%)^{*}$ & $22(79)$ & $22(79)$ & .49 & $24(86)$ & .15 \\
\hline Time with $\mathrm{S}_{\mathrm{pO}_{2}}<90 \%, \%$ & $34.1 \pm 3.5$ & $25.1 \pm 3.5$ & .07 & $19.8 \pm 3.5$ & .005 \\
\hline \multicolumn{6}{|l|}{ Immediately after $6 \mathrm{MWT}$} \\
\hline $\mathrm{S}_{\mathrm{pO}_{2}}, \%$ & $89.4 \pm 0.3$ & $89.4 \pm 0.3$ & .99 & $90.8 \pm 0.3$ & .003 \\
\hline Breathing frequency, breaths/min & $23.3 \pm 0.5$ & $24.2 \pm 0.5$ & .25 & $22.8 \pm 0.5$ & .52 \\
\hline Heart rate, beats/min & $99.9 \pm 1.5$ & $98.5 \pm 1.5$ & .49 & $95.3 \pm 1.5$ & .03 \\
\hline Borg dyspnea score & $3.4 \pm 0.2$ & $3.0 \pm 0.2$ & .16 & $3.6 \pm 0.2$ & .60 \\
\hline 6-min walk distance, $\mathrm{m}$ & $352.2 \pm 2.2$ & $347.9 \pm 2.1$ & .16 & $346.5 \pm 2.1$ & .07 \\
\hline \multicolumn{6}{|c|}{$\begin{array}{l}\text { Values are least-squares means } \pm \text { standard error of the mean for continuous variables unless otherwise indicated. } \\
* \text { Correction of desaturation was defined as average } \mathrm{S}_{\mathrm{pO}_{2}} \geq 90 \% \text {. } \\
\text { CFNC }=\text { continuous flow with standard nasal cannula } \\
\text { DOD }=\text { demand oxygen delivery oxygen device } \\
\mathrm{PRC}=\text { pendant reservoir cannula } \\
6 \mathrm{MWT}=6 \text {-min walk test }\end{array}$} \\
\hline
\end{tabular}



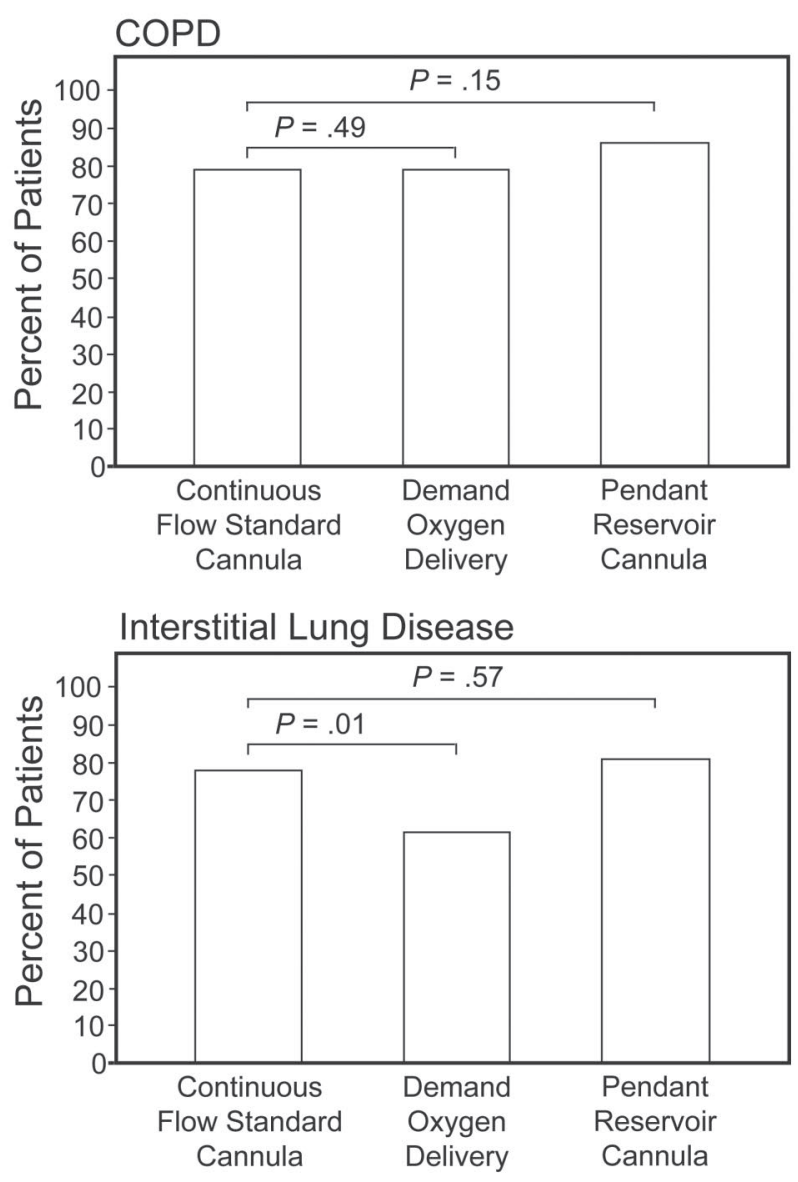

Fig. 2. Correction of exercise oxygen desaturation (6-min walk test average $\mathrm{S}_{\mathrm{pO}_{2}} \geq 90 \%$ ) with the 3 oxygen supplementation systems tested, in subjects with COPD and subjects with interstitial lung disease.

cise: average $\mathrm{S}_{\mathrm{pO}_{2}}$ was $81 \%$ in the COPD subjects and $80 \%$ in the ILD subjects (Table 2).

\section{COPD Subjects}

On oxygen supplementation by CFNC, desaturation during exercise was corrected in $79 \%$ of the COPD subjects (Table 3 and Fig. 2). In the remaining 21\%, desaturation correction was not achieved even at the highest flow available on the device. When the oxygen-conserving devices were used, correction was achieved in $79 \%$ of subjects with the DOD and $86 \%$ with the PRC. The final adjusted median (and IQR) oxygen settings in the 28 COPD subjects were 4 (3-5.5) for CFNC, 4 (3-5) for DOD, and 3 (2-4) for PRC. The number of subjects in whom desaturation was corrected, the dyspnea scores, and the walk distances were similar with the 3 systems tested (see Table 3). Although 75\% of the COPD subjects preferred the DOD system and only $11 \%$ preferred CFNC or PRC, the difference was not statistically significant $(P$ for pref- erence 0.43 ); 1 COPD subject (3\%) did not prefer one system over any other.

\section{ILD Subjects}

Correction of desaturation was achieved in $77 \%$ of the ILD subjects with CFNC, $61 \%$ with the DOD, and $81 \%$ with the PRC (Table 4 and Fig. 2). Thus, nearly $40 \%$ of the ILD subjects using the DOD system did not attain correction even with the highest setting, and performance was poorer than that with CFNC $(P=.01)$. The adjusted median (and IQR) oxygen settings in the 31 ILD subjects were 5 (3-6) for CFNC, 5 (3-5) for DOD, and 4 (2-5) for PRC. Despite the poorer $\mathrm{S}_{\mathrm{pO}_{2}}$ correction with the DOD system, no differences were found between the 2 oxygenconserving devices and CFNC in dyspnea score or walk distance (see Table 4). CFNC was the system of choice in $35 \%$ of the ILD subjects, $35 \%$ chose DOD, and only $6 \%$ preferred PRC. Five ILD subjects (24\%) did not prefer one system over any other $(P=.33)$.

\section{Discussion}

Although the oxygen-conserving devices were effective in correcting exercise hypoxemia in most of the COPD and ILD subjects, there remained a considerable percentage of subjects in whom correction was not achieved. The lack of correction was more pronounced in the ILD subjects with the DOD, even though the oxygen flow was increased to the maximum.

Variation in the response to DOD devices according to the subjects' underlying disease has not been previously reported. Palwai et $\mathrm{al}^{15}$ assessed the performance of 4 DOD systems, both in technical terms, in a bench study, and clinically, in 13 COPD subjects. Although all the devices tested were activated during nose and mouth breathing, there was poor synchronization between triggering and inspiration, and major discrepancies were found between the predicted and actual amounts of oxygen delivered. Palwai et al found that performance was devicedependent rather than subject-dependent. It may be hypothesized that different respiratory patterns between COPD subjects and ILD subjects could be implicated in our results. The mean breathing frequency recorded at completion of exercise was 23 breaths/min in the COPD subjects and 32 breaths/min in the ILD subjects, and this difference could have had an impact on our results, mainly because of 2 factors. First, the efficacy of oxygen delivery systems in terms of $\mathrm{F}_{\mathrm{IO}_{2}}$ is inversely related to the breathing frequency. ${ }^{7}$ Second, the higher breathing frequency in ILD subjects may place a stress on the mechanical performance of these devices, which are reported to have some technical limitations. ${ }^{15}$ Although the DOD system we chose for the present study has good trigger sensi- 


\section{Are Oxygen-Conserving Devices Effective for Correcting Exercise Hypoxemia?}

Table 4. Cardiopulmonary Measurements in the ILD Subjects, at Rest Before, During, and After the 6-Min Walk Test With 3 Oxygen Delivery Systems $(n=31)$

\begin{tabular}{|c|c|c|c|c|c|}
\hline & CFNC & DOD & $\begin{array}{c}P \\
\text { DOD vs CFNC }\end{array}$ & PRC & $\begin{array}{c}P \\
\text { PRC vs CFNC }\end{array}$ \\
\hline \multicolumn{6}{|l|}{ At rest before $6 \mathrm{MWT}$} \\
\hline $\mathrm{S}_{\mathrm{pO}_{2}}, \%$ & $97.2 \pm 0.3$ & $96.2 \pm 0.3$ & .009 & $97.4 \pm 0.3$ & .78 \\
\hline Breathing frequency, breaths/min & $26.8 \pm 1.1$ & $26.8 \pm 1.1$ & $>.99$ & $29.0 \pm 1.1$ & .16 \\
\hline Heart rate, beats/min & $78.9 \pm 1.1$ & $79.9 \pm 1.1$ & .51 & $80.6 \pm 1.1$ & .29 \\
\hline Borg dyspnea score & $0.4 \pm 0.1$ & $0.6 \pm 0.1$ & .24 & $0.7 \pm 0.1$ & .03 \\
\hline \multicolumn{6}{|l|}{ During 6MWT } \\
\hline Average $\mathrm{S}_{\mathrm{pO}_{2}}, \%$ & $90.9 \pm 0.3$ & $89.4 \pm 0.3$ & .001 & $91.8 \pm 0.3$ & .07 \\
\hline Average $\mathrm{S}_{\mathrm{pO}_{2}} \geq 90 \%$, no. $(\%)^{*}$ & $24(77)$ & $19(61)$ & .01 & $25(81)$ & .57 \\
\hline Time with $\mathrm{S}_{\mathrm{pO}_{2}}<90 \%, \%$ & $40.0 \pm 3.5$ & $46.0 \pm 3.5$ & .24 & $28.5 \pm 3.5$ & .02 \\
\hline \multicolumn{6}{|l|}{ Immediately after $6 \mathrm{MWT}$} \\
\hline $\mathrm{S}_{\mathrm{pO}_{2}}, \%$ & $88.3 \pm 0.4$ & $86.6 \pm 0.4$ & .005 & $89.9 \pm 0.4$ & .01 \\
\hline Breathing frequency, breaths/min & $32.6 \pm 0.7$ & $31.4 \pm 0.7$ & .24 & $33.1 \pm 0.7$ & .59 \\
\hline Heart rate, beats/min & $106.1 \pm 1.3$ & $105.6 \pm 1.3$ & .80 & $101.8 \pm 1.3$ & .03 \\
\hline Borg dyspnea score & $4.1 \pm 0.1$ & $3.9 \pm 0.1$ & .55 & $3.8 \pm 0.1$ & .25 \\
\hline 6-min walk distance, $\mathrm{m}$ & $348.0 \pm 3.0$ & $347.9 \pm 3.0$ & .97 & $346.7 \pm 3.0$ & .75 \\
\hline $\begin{array}{l}\text { Values are least-squares means } \pm \text { standard error } \\
* \text { Correction of desaturation was defined as aver } \\
\text { ILD }=\text { interstitial lung disease } \\
\text { CFNC = continuous flow with standard nasal ca } \\
\text { DOD = demand oxygen delivery oxygen device } \\
\text { PRC }=\text { pendant reservoir cannula } \\
6 \text { MWT = 6-min walk test }\end{array}$ & $\begin{array}{l}\text { an for continuous } \\
=90 \% \text {. }\end{array}$ & Inless otherwise in & & & \\
\hline
\end{tabular}

tivity $\left(0.14 \mathrm{~cm} \mathrm{H}_{2} \mathrm{O}\right)$, an important factor related to its efficacy, ${ }^{12}$ and is able to deliver $\mathrm{F}_{\mathrm{IO}_{2}}$ of nearly 0.40 at 15 breaths/min and $35 \%$ at 30 breaths/min at the maximum output (setting 5), ${ }^{7}$ we cannot exclude that limitations may manifest in clinical practice in highly demanding conditions, particularly in ILD patients.

We analyzed 31 subjects with ILD, and the efficacies of CFNC and PRC were similar, with correction of $\mathrm{S}_{\mathrm{pO}_{2}}$ in around $80 \%$ of the ILD subjects, whereas with DOD only $61 \%$ of the ILD subjects achieved correction. Previous studies have evaluated oxygen-conserving device performance in ILD, ${ }^{17,26,27}$ but the small number of subjects $(<10)$ in those studies makes it difficult to extract universally applicable conclusions. In contrast to our findings, studies assessing various DOD systems ${ }^{26,27}$ have reported performance equivalent to the continuous flow types. However, those devices were tested at a low level of exercise, so their efficacy was not examined under technical or physiological stress. Therefore, our results provide a new view of these devices and indicate some difficulty in correcting $\mathrm{S}_{\mathrm{pO}_{2}}$ in some ILD patients with a DOD system.

The DOD system was the device of choice in $75 \%$ of the COPD subjects. In contrast, the PRC system was preferred by only 2 ILD subjects (6\%), even though it had the greatest efficacy in correcting their desaturation (see Fig. 2). This finding seems to indicate that patients prioritize es- thetics and comfort (eg, cannula size and weight of the device) over other factors. Acceptance of PRC was assessed in a previous study in 17 subjects with COPD and 4 with restrictive lung disease. ${ }^{28}$ Following 1 month of home use, 9 of the 21 subjects had abandoned the PRC, citing bulkiness and discomfort as the factors leading to poor adherence. Therefore, despite the good results with the PRC in our subjects, poor acceptance of PRC might limit its application.

Our study has some limitations that should be considered when interpreting the results. The first is our selection of the 6MWT to evaluate exercise hypoxemia. The 6MWT evaluates the global and integrated responses of the pulmonary, cardiovascular, and muscular systems, and is easily performed, well tolerated, reproducible, and a good reflection of the activities of daily living. ${ }^{23,29}$ In the context of long-term oxygen therapy there are no uniform criteria for evaluating and adjusting oxygen flow on exercise, but the 6MWT is the most commonly used test, and the oxygen flow required to maintain $\mathrm{S}_{\mathrm{pO}_{2}} \geq 90 \%$ is a commonly used threshold. ${ }^{30}$ Therefore, this value was used in the present study to establish adequate $\mathrm{S}_{\mathrm{pO}_{2}}$ when walking with oxygen supplementation.

Second, the study was performed in the oxygen therapy units of 2 reference hospitals, in which the subjects are more likely to have severe disease, and $\mathrm{S}_{\mathrm{pO}_{2}}$ correction is more likely to fail than in settings where less severe cases 


\section{Are Oxygen-Conserving Devices Effective for Correcting Exercise Hypoxemia?}

are treated. Nonetheless, the findings should alert clinicians evaluating these patients for oxygen therapy that the more severe cases (eg, low carbon monoxide diffusion, high lung hyperinflation, marked desaturation on exercise, high-flow oxygen requirements) may not achieve resaturation with the device chosen.

Third, our assessment was carried out at a single time point, using a 6MWT, so our results do not necessarily reflect the acceptance and effectiveness of this treatment in patients' daily lives. ${ }^{31}$ Longer-term studies are needed to determine the impact on quality of life of the various oxygen-conserving devices.

Fourth, we tested only one of the multiple valve systems on the market, and our findings cannot be generalized to other available DOD devices. However, our results support the notion that these systems may have limitations in certain groups of patients, as has been previously reported..$^{15}$

\section{Conclusions}

Around $20 \%$ of the severe COPD subjects with oxygen desaturation did not achieve resaturation during the 6MWT, even when oxygen flow was increased to the maximum with 3 portable oxygen systems. Moreover, failure to correct desaturation occurred in $40 \%$ of the ILD subjects when exercising with the pulse DOD device. These findings underscore the need to individually adjust oxygen flow during exercise for each patient with the device being considered for use. Furthermore, in the light of these findings, it would be advisable to carry out studies evaluating the benefits of new portable oxygen delivery systems that can provide greater flow.

\section{REFERENCES}

1. Davidson AC, Leach R, George RJ, Geddes DM. Supplemental oxygen and exercise ability in chronic obstructive airways disease. Thorax 1988;43(12):965-971.

2. Waterhouse JC, Howard P. Breathlessness and portable oxygen in chronic obstructive airways disease. Thorax 1983;38(4):302-306.

3. Harris-Eze AO, Sridhar G, Clemens RE, Gallagher CG, Marciniuk DD. Oxygen improves maximal exercise performance in interstitial lung disease. Am J Respir Crit Care Med 1994;150(6 Pt 1):1616-1622.

4. Leach RM, Davidson AC, Chinn S, Twort CHC, Cameron IR, Bateman NT. Portable liquid oxygen and exercise ability in severe respiratory disability. Thorax 1992;47(10):781-789.

5. Dunne PJ. The clinical impact of new long-term oxygen therapy technology. Respir Care 2009;54(8):1100-1111.

6. Petty TL, Casaburi R. Recommendations of the Fifth Oxygen Consensus Conference. Writing and Organizing Committees. Respir Care 2000;45(8):957-961.
7. Bliss PL, McCoy RW, Adams AB. Characteristics of demand oxygen delivery systems: maximum output and setting recommendations. Respir Care 2004;49(2):160-165.

8. Christopher KL, Porte P. Long-term oxygen therapy. Chest 2011; 139(2):430-434.

9. Bower JS, Brook CJ, Zimmer K, Davis D. Performance of a demand oxygen saver system during rest, exercise, and sleep in hypoxemic patients. Chest 1988;94(1):77-80.

10. Braun SR, Spratt G, Scott GC, Ellersieck M. Comparison of six oxygen delivery systems for COPD patients at rest during exercise. Chest 1992;102(3):694-698.

11. Tiep BL, Barnett J, Schiffman G, Sánchez O, Carter R. Maintaining oxygenation via demand oxygen delivery during rest and exercise. Respir Care 2002;47(8):887-892.

12. Fuhrman C, Chouaid C, Herigault R, Housset B, Adnot S. Comparison of four demand oxygen delivery systems at rest and during exercise for chronic obstructive pulmonary disease. Respir Med 2004; 98(10):938-944.

13. Garrod R, Bestall JC, Paul E, Wedzicha JA. Evaluation of pulsed dose oxygen delivery during exercise in patients with severe chronic obstructive pulmonary disease. Thorax 1999;54(3):242-244.

14. Hagarty EM, Skorodin MS, Langbein WE, Hultman CI, Jessen JA, and Maki KC. Comparison of three oxygen delivery systems during exercise in hypoxemic patients with chronic obstructive pulmonary disease. Am J Respir Crit Care Med 1997;155(3): 893-898.

15. Palwai A, Skowronski M, Coreno A, Drummond C, and McFadden ER. Critical comparisons of the clinical performance of oxygenconserving devices. Am J Respir Crit Care Med 2010;181(10): 1061-1071.

16. Roberts CM, Bell J, Wedzicha JA. Comparison of the efficacy of a demand oxygen delivery system with continuous low flow oxygen in subjects with stable COPD and severe oxygen desaturation on walking. Thorax 1996;51(8):831-834.

17. Arlati S, Rolo J, Micallef E, Sacerdoti C, and Brambilla I. A reservoir nasal cannula improves protection given by oxygen during muscular exercise in COPD. Chest 1988;93(6):1165-1169.

18. Celli BR, MacNee W. Standards for the diagnosis and treatment of patients with COPD: a summary of the ATS/ERS position paper. Eur Respir J 2004;23(6):932-946.

19. American Thoracic Society/European Respiratory Society International Multidisciplinary Consensus Classification of the Idiopathic Interstitial Pneumonias. Am J Respir Crit Care Med 2002; 165(2):277-304. Erratum in: Am J Respir Crit Care Med 2002; 166(3):426.

20. Miller MR, Hankinson J, Brusasco V, Burgos F, Casaburi R, Coates A, et al. Standardisation of spirometry. Eur Respir J 2005; 26(2):319-338.

21. MacIntyre NR, Crapo RO, Viegi G, Johnson DC, van der Grinten $\mathrm{CP}$, Brusasco V, et al. Standardisation of the single-breath determination of carbon monoxide uptake in the lung. Eur Respir J 2005; 26(4):720-735.

22. Bestall JC, Paul EA, Garrod R, Garnham R, Jones PW, Wedzicha JA. Usefulness of the Medical Research Council (MRC) dyspnoea scale as a measure of disability in patients with chronic obstructive pulmonary disease. Thorax 1999;54(7):581-586.

23. American Thoracic Society. ATS statement: guidelines for the sixminute walk test. Am J Respir Crit Care Med 2002;166(1):111-117.

24. Borg GA. Psychophysical bases of perceived exertion. Med Sci Sports Exerc 1982;14(5):377-381.

25. Stephen S. Cross-over trials in clinical research. New York: John Wiley; 1993. 
26. Carter R, Tashkin D, Djahed B, Hathaway E, Nicotra MB, Tiep BL. Demand oxygen delivery for patients with restrictive lung disease. Chest 1989;96(6):1307-1311.

27. Senn S, Wanger J, Fernandez E, Cherniack RM. Efficacy of a pulsed oxygen delivery device during exercise in patients with chronic respiratory disease. Chest 1989;96(3):467-472.

28. Claiborne RA, Paynter DE, Dutt AK, Rowlands JW. Evaluation of the use of an oxygen conservation device in long-term oxygen therapy. Am Rev Respir Dis 1987;136(5):1095-1098.
29. Morante F, Guell R, Mayos M. Efficacy of the 6-minute walk test in evaluating ambulatory oxygen therapy. Arch Bronconeumol 2005; 41(11):596-600.

30. Wijkstra PJ, Guyatt GH, Ambrosino N, Celli BR, Güell R, Muir JF, et al. International approaches to the prescription of long-term oxygen therapy. Eur Respir J 2001;18(6):909-913.

31. Eaton T, Garrett JE, Young P, Fergusson W, Kolbe J, Rudkin S, Whyte $\mathrm{K}$. Ambulatory oxygen improves quality of life of COPD patients: a randomised controlled study. Eur Respir J 2002;20(2):306-312.

This article is approved for Continuing Respiratory Care Education credit. For information and to obtain your CRCE

(free to AARC members) visit www.rcjournal.com 